in vivo $33: 1-10(2019)$

doi:10.21873/invivo.11431

Review

\title{
Reconstructive Surgery of Inguinal Defects: A Systematic Literature Review of Surgical Etiology and Reconstructive Technique
}

\author{
KARL SÖRELIUS $^{1 *}$, LUIGI SCHIRALDI ${ }^{2 *}$, SALVATORE GIORDANO ${ }^{3}$, \\ CARLO M. ORANGES ${ }^{4}$, WASSIM RAFFOUL ${ }^{2}$ and PIETRO G. DI SUMMA ${ }^{2}$ \\ ${ }^{1}$ Department of Surgical Sciences, Section of Vascular Surgery, Uppsala University, Uppsala, Sweden; \\ ${ }^{2}$ Department of Plastic, Reconstructive and Hand Surgery, \\ Lausanne University Hospital (CHUV), Lausanne, Switzerland; \\ ${ }^{3}$ Department of Plastic and General Surgery, Turku University Hospital, Turku, Finland; \\ ${ }^{4}$ Department of Plastic, Reconstructive, Aesthetic and Hand Surgery, Basel University Hospital, Basel, Switzerland
}

\begin{abstract}
Background/Aim: This study aimed to evaluate the literature regarding surgical etiology demanding inguinal reconstructive surgery, associated reconstructive techniques and outcomes. Materials and Methods: A systematic literature search was performed according to the PRISMA statement between 1996-2016. Results: A total of 64 articles were included, comprising 816 patients. Two main subgroups of patients were identified: Oncological resections $(n=255,31 \%)$, and vascular surgery $(n=538,66 \%)$. Oncological resection inguinal defects were treated with pedicled myocutaneous flaps $(n=166,65 \%)$, fasciocutaneous flaps $(77,31 \%)$, muscle flaps $(7,3 \%)$ and direct closure $(3,1 \%)$. Vascular surgery complications were treated with muscle flaps $(n=513,95 \%)$. Complications for the respective subgroup (oncological resections, vascular surgery) were: infection $(24 \%, 14 \%)$, seroma $(34 \%, 7.5 \%)$, flap dehiscenceldelayed healing $(20.6 \%, 40.8 \%$,). The total reintervention rate was $20 \%$. Conclusion: Reconstruction of inguinal defects should be addressed on a case-by-case basis. Myocutaneous flaps were favoured after oncological resections, while muscle flaps were preferred after vascular surgery.
\end{abstract}

This article is freely accessible online.

*These Authors contributed equally to this study.

Correspondence to: Pietro G. di Summa, Department of Plastic, Reconstructive and Hand Surgery, University Hospital of Lausanne (CHUV), Rue du Bugnon 46, 1011 Lausanne, Switzerland. Tel: +41 213141111, e-mail: pietro.di-summa@chuv.ch

Key Words: Oncological surgery, vascular surgery, inguinal defect, reconstructive surgery, complications, review.
The inguinal region represents a crucial intersection of fundamental anatomical structures, such as the femoral artery, vein, nerve, the inguinal node stations and the inguinal canal. This makes the inguinal carrefour a common surgical site for interventions that range from surgical lymphadenectomy, diverse oncological resections to a number of vascular, visceral and urological surgical procedures. Such procedures may result in soft tissue defects and exposure of key anatomic elements, requiring reconstruction. However, if radical inguinal oncological surgery is more likely to produce a primary defect or dead space, vascular and general surgery procedures, may incur wound dehiscence, delayed healing, and abscess formation, finally requiring radical aggressive debridement leading to a secondary soft tissue and skin defect.

The anatomical features of inguinal defects in the particular location between the abdominal and the thigh, and in the vicinity of the anogenital region, make the reconstruction of the inguinal region challenging for the plastic surgeon. The poor healing of wounds in the inguinal region has been attributed to wide defects with bacterial contamination, noncollapsible dead spaces, lymphatic leaks and the healing difficulties related to a low vascularized, or eventually irradiated field $(1,2)$, depending on the primary pathology. The post-operative morbidity associated with inguinal surgery is well documented in the literature, with an incidence of complications as high as $40 \%$ (3).

The aims of this systematic literature review were to comprehensively review the last two decades of literature concerning inguinal reconstructions, focusing on etiology, and associated reconstruction techniques and outcomes with complications associated with respective etiology and 
reconstructive technique. This might aid everyday clinical decision-making and treatment of complex groin defects.

\section{Methods}

A systematic search of the literature was performed on PubMed and Medline on manuscripts in English language between 1st of January 1996 until 31st of December 2016. The following algorithm was used for the research [(groin OR inguinal) AND (reconstruction OR defect) AND (wound OR infection)].

A prefilled excel database was used to enter the records according to a defined exclusion criteria algorithm. Case reports, case series and larger cohorts were all accepted for inclusion. Exclusion criteria applied hierarchically were: (I) not relevant to groin tissues reconstruction; (II) groin as donor site; (III) not in English; (IV) review article.

Abstracts were manually screened by authors LS and PDS separately, and subsequently matched for accuracy. Pertinent fulltext papers were retrieved and analysed, and data were extracted on the database. The flow chart of article selection is described following the Preferred Reporting Items for Systematic Reviews and Meta-Analyses (PRISMA) statement (Figure 1) (4). All papers were graded by PDS and KS according to the GRADE and PRISMA documents (5).

Statistical analysis. Data were analyzed using a statistical software package (GraphPad Prism 5.00, San Diego, USA).

Data were assessed for normality with histograms. Continuous data were expressed as median (range), or mean (standard deviation, $\mathrm{SD})$ and categorical variables as proportions (\%).

\section{Results}

Study selection. The initial database literature search yielded 1,019 records, including duplicates and non-pertinent articles. After manual screening of the abstracts, 907 records were excluded as non-pertinent to our search. The remaining 112 articles were further assessed for eligibility; 26 articles referred to inguinal donor site, 17 articles not pertinent to inguinal reconstruction, 4 reviews or editorials, and 2 articles not English language, and hence were excluded from data analysis. A total of 64 articles were identified and included for data extraction and quantitative analysis (Figure 1). There were zero randomized controlled trials, 6 prospective studies, and 58 retrospective studies.

Overall demographic data. The 64 included studies comprised a total of 816 patients, who all underwent surgical reconstruction of an inguinal defect. The mean age was 55.7 years $(\mathrm{SD} \pm 14.25$, range $=17-92$ years), and male sex $(57.7 \%)$. No meta-analyses were possible to perform due to study heterogeneity, variable end-points and lack of data, and lack of bias assessment.

Thirty-four papers of 255 patients, reported on reconstruction following oncological resection defects (639): 122 patients were affected by a primary neoplasia of the
Table I. All types of flaps reported for reconstructive surgery of inguinal defects for each subgroup of patients.

\begin{tabular}{lccc}
\hline Types of flaps & $\begin{array}{c}\text { Subgroup } \\
\text { of onc. } \\
\text { resections, } n\end{array}$ & $\begin{array}{c}\text { Subgroup } \\
\text { of vasc. } \\
\text { surgery, } \mathrm{n}\end{array}$ & $\begin{array}{c}\text { Subgroup } \\
\text { of misc. } \\
\text { etiology, } \mathrm{n}\end{array}$ \\
\hline Myocutaneous flaps & 71 & 10 & 4 \\
RA-MC & 63 & 3 & 3 \\
ALT-MC & 20 & - & 2 \\
TFL-MC & - & - & 4 \\
VL-MC & 7 & - & - \\
EOMF-MC & 3 & - & - \\
LD-MC & 3 & 5 & - \\
RF-MC & 2 & & - \\
G-MC & & 8 & 9 \\
Fasciocutaneous flaps & 45 & - & - \\
ALT-FC & 20 & - & - \\
QKIF-FC & 8 & - & - \\
TFL-FC & 2 & - & - \\
PMT-FC & 2 & 1 & - \\
DIEP-FC & 2 & 1 & 1 \\
PSA-FC & 2 & 2 & - \\
Local Flap & & 117 & - \\
Muscle flaps & 4 & 293 & - \\
RA-M & 1 & 98 & - \\
RF-M & 4 & & \\
S-M & & & \\
G-M & & & \\
\hline
\end{tabular}

Onc: Oncological; vasc: vascular; misc: miscellaneous; n: number; RA; rectus abdominis flap; S: sartorius flap; TFL: tensor fascia latae flap; VL: vastus lateralis flap; DIEP: deep inferior epigastric artery perforator flap; ALT: anterolateral tight flap; G: gracilis flap; RF: rectus femoris flap; QKIF: quadriceps keystone island flap; EOMF: external oblique myocutaneous flap; S-FAP: superficial femoral artery perforator flap; LD: latissimus dorsi flap; ORAM: oblique rectus abdominis flap; PMT: posterior posteromedial tight flap; M: muscular; FC: fasciocutaneous; MC: myocutaneous.

inguinal area, and 133 patients were suffering from nodal dissemination from a malignancy of genitalia, perineum or lower limbs.

Twenty-two studies, including 538 patients, reported on inguinal reconstruction following vascular surgery: cannulation of femoral artery or vein, aorto-femoral or femoro-popliteal bypass, and often not specified (2, 5-25). Others causes leading to inguinal defect requiring reconstructive surgery involved trauma (four papers of 11 patients) (26-29), infections (three papers of 10 patients) (2, 26,30 ), post burn contractions (one paper of 1 patient) (31), and one paper of a strangulated inguinal hernia with parietal abscess and necrosis of 23 patients (40). All flap types used for each subgroup are presented in Table I.

Hospital stay and follow-up. Fifteen papers reported on the length of hospitalisation $(10,16,17,22,23,27,32-39,41)$. The average hospital stay after the reconstruction was 


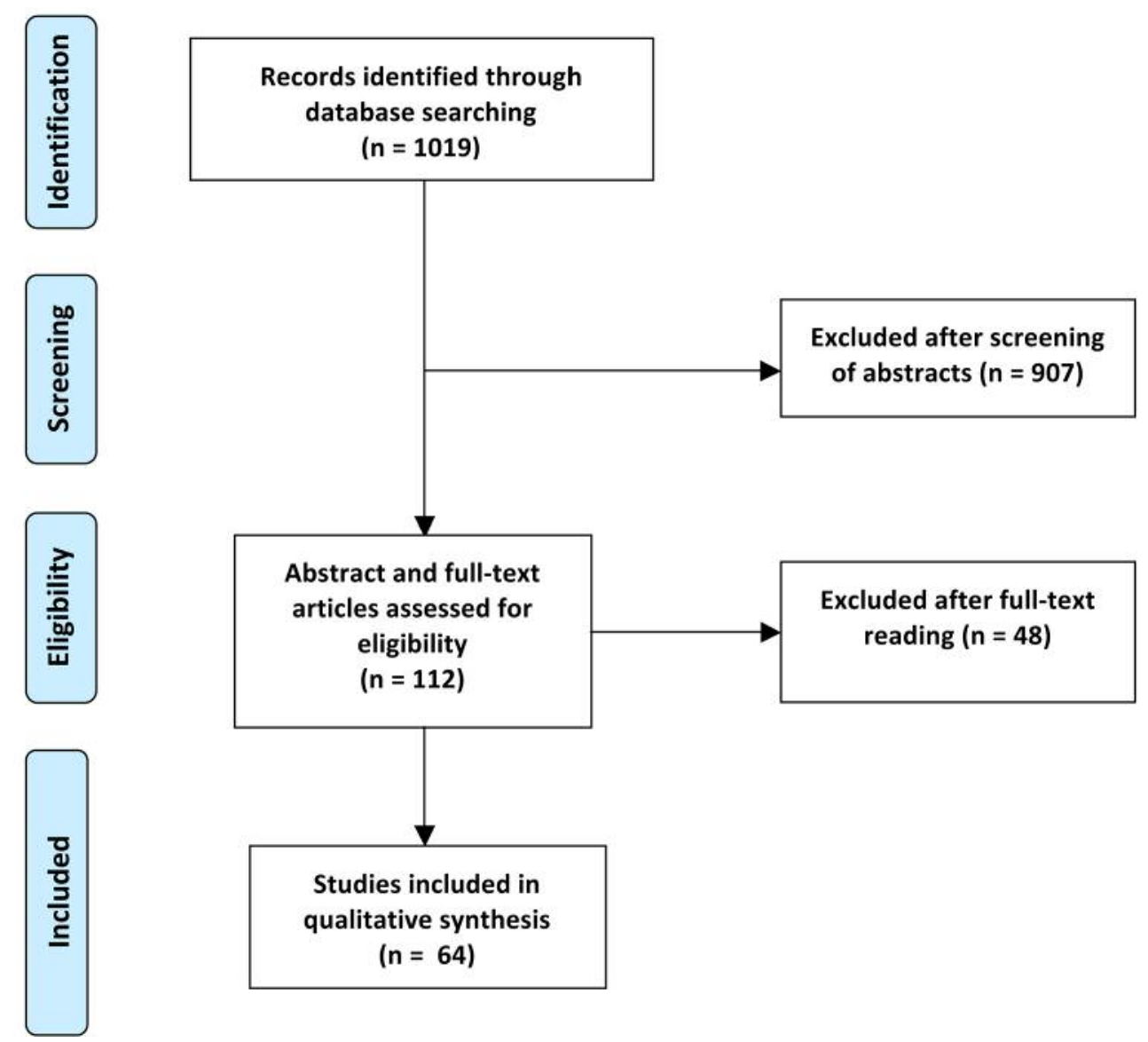

Figure 1. PRISMA Flow diagram.

12.1 \pm 6.2 days and 14.2 \pm 5.8 days (all expressed as mean $\pm \mathrm{SD}$ ), for oncological and vascular patients, respectively.

Patients with inguinal reconstruction after oncological resection had a follow-up period of $23.7 \pm 18.1$ (months, mean \pm SD) with a range of $0-184$ months. Patients with inguinal reconstruction after vascular surgery had a followup of $19.0 \pm 18.7$ (months, mean \pm SD) with a range of $1-108$ months. The other patients had a follow-up of 12.0 17.7 months (mean $\pm \mathrm{SD})$.

\section{Reconstruction Technique}

The subgroup of oncological resections. Out of 255 patients who underwent inguinal oncological reconstruction, 166 had reconstruction with a myocutaneous (MC) flap, 77 reconstruction with a fasciocutaneous (FC) flap 9 muscle (M) flap, and 3 direct closure after debridement. Flaps used in the vast majority of cases were pedicled, only one paper reported on the use of free flaps: Three patients received free latissimius dorsi (LD-MC) flap, and two patients free anterolateral thigh (ALT-FC) flap (26).
The flap was harvested unilaterally in 253 cases, and bilaterally in 2 cases, to cover the inguinal defect. The recipient site was ipsilateral to the flap in 245 patients, and contralateral in 10 patients. The most common used flap in this group of patients was the rectus abdominis myocutaneous (RA-MC) flap $(\mathrm{n}=71,28.0 \%)$, antero-lateral thigh myocutaneous (ALT-MC) flap $(n=63,25 \%)$, and antero-lateral thigh fasciocutaneous (ALT-FC) flap $(n=45$, $18 \%$ ). Complete results are summarized in Table II.

After oncologic resection, the average dimension of cutaneous and subcutaneous defect was $252.6 \pm 226.1 \mathrm{~cm}^{2}$ (mean \pm SD) ranging from $163.1 \pm 103.1 \mathrm{~cm}^{2}$ (mean \pm SD) to $336.6 \pm 284.2$, with an average minor and maximal axis of $9.2 \pm 3.6 \mathrm{~cm}($ mean \pm SD) and 22.6 $\pm 9.8($ mean \pm SD) $\mathrm{cm}$, respectively. A considerable part of these patients $(83.2 \%)$ had been treated with prior neoadjuvant radiotherapy.

The subgroup of vascular surgery. Of the total 538 patients treated for diverse vascular surgical procedures, the vascular coverage was performed with a muscle flap in 513 cases (95\%); sartorius muscle (S-M) flap in 293 patients $(54.5 \%)$, 
in vivo $33: 1-10(2019)$

Table II. Publications including patients with oncological resections demanding for reconstructive inguinal surgery.

\begin{tabular}{|c|c|c|c|c|c|c|c|c|}
\hline Author, Year & Country & Design & $\begin{array}{c}\text { Number of } \\
\text { patients }\end{array}$ & $\begin{array}{l}\text { Age } \\
\text { (mean) }\end{array}$ & $\begin{array}{c}\mathrm{LN} \\
\text { dissemination }\end{array}$ & $\begin{array}{l}\text { Coverage } \\
\text { technique }\end{array}$ & $\begin{array}{l}\text { Follow-up } \\
\text { (months) }\end{array}$ & GRADE \\
\hline Brierly, 1998 & UK & $\mathrm{R}$ & 1 & 42 & 1 & RA-MC & 9 & Very low \\
\hline Melis, 1998 & Netherlands & $\mathrm{R}$ & 1 & 44 & 1 & S-M & n.a. & Very low \\
\hline Deo, 2001 & India & $\mathrm{R}$ & 2 & 42 & 1 & RA-MC & $32(8-68)$ & Very low \\
\hline Mohamed, 2000 & Egypt & $\mathrm{R}$ & 1 & 48 & 0 & RA-MC & $48.5(36-56)$ & Very low \\
\hline Tabatabei, 2003 & USA & $\mathrm{R}$ & 3 & 58 & 3 & $\begin{array}{l}\text { Abdominal advancement } \\
\text { cutaneous flap+S-M }\end{array}$ & $6(4-8)$ & Very low \\
\hline Rifaat, 2005 & Egypt & $\mathrm{R}$ & 6 & n.a. & 2 & TFL-FC & $6-24$ & Very low \\
\hline Zeng, 2006 & China & $\mathrm{R}$ & 2 & 36 & 2 & DIEP & n.a. & Very low \\
\hline Küntscher, 2006 & Germany & $\mathrm{R}$ & 1 & 57 & 1 & RA-MC & n.a. & Very low \\
\hline Cedidi, 2006 & Germany & $\mathrm{R}$ & 2 & n.a. & 0 & RA-MC & 12 & Very low \\
\hline Evriviades, 2007 & UK & $\mathrm{P}$ & 6 & 68 & 6 & ALT-FC & 6 & Low \\
\hline Parrett, 2007 & USA & $\mathrm{R}$ & 20 & 56 & 0 & RA-MC & 28 & Very low \\
\hline $\mathrm{Ng}, 2007$ & China & $\mathrm{R}$ & 1 & 69 & 1 & ALT-FC & n.a. & Very low \\
\hline Qi, 2008 & China & $\mathrm{R}$ & 13 & 49 & 10 & RA-MC & n.a. & Very low \\
\hline El-Sherbiny, 2008 & Egypt & $\mathrm{P}$ & 10 & 39 & 0 & $\begin{array}{c}\text { G-MC } 2 \text {, RA-MC 5, TFL-MC } 1, \\
\text { ALT-FC + S-M } 1\end{array}$ & 60 & Low \\
\hline Agarwal, 2009 & India & $\mathrm{R}$ & 15 & 46 & 15 & TFL-MC & 36 & Very low \\
\hline Friji, 2009 & India & $\mathrm{R}$ & 56 & n.a. & 56 & ALT-MC & n.a. & Low \\
\hline Gravvanis, 2009 & UK & $\mathrm{R}$ & 4 & 52 & 4 & ALT-FC & $11-19$ & Very low \\
\hline Ramseier, 2009 & Switzerland & $\mathrm{R}$ & 7 & n.a. & 0 & RA-M 3, RF-M 1, direct closure 3 & n.a. & Very low \\
\hline Lannon, 2010 & Canada & $\mathrm{R}$ & 18 & 63 & 4 & ALT-FC & n.a. & Very low \\
\hline Bharath, 2010 & India & $\mathrm{R}$ & 1 & 65 & 0 & ALT-MC & n.a. & Very low \\
\hline Daigeler, 2011 & Germany & $\mathrm{P}$ & 6 & 58 & 3 & RA-MC & $66(7-184)$ & Very low \\
\hline Behan, 2011 & Australia & $\mathrm{P}$ & 20 & 71 & 20 & QKIF-FC & & Moderate \\
\hline Saito, 2013 & Japan & $\mathrm{R}$ & 5 & 62 & 0 & TFL-MC 2,TF-M (+VL-M) 3 & $37(0-116)$ & Very low \\
\hline LoGiudice, 2013 & USA & $\mathrm{R}$ & 39 & 60 & 0 & ALT-FC 28, ALT-MC 2, RA-MC 10 & 12 & Very low \\
\hline Sánchez, 2013 & UK & $\mathrm{R}$ & 2 & 67 & 0 & RA-MC & 24 & Very low \\
\hline Zhang, 2014 & China & $\mathrm{R}$ & 7 & 59 & 0 & EOMF-MC & 6 & Very low \\
\hline Chao, 2014 & USA & $\mathrm{R}$ & 1 & 63 & 1 & ALT-FC & 2 & Very low \\
\hline Miyamoto, 2014 & Japan & $\mathrm{R}$ & 3 & 50 & 0 & S-FAP & 8 & Very low \\
\hline Miyamoto S, 2014 & Japan & $\mathrm{R}$ & 12 & 48 & 0 & $\begin{array}{l}\text { Pedicled RA-MC 7, free LD-MC 7, } \\
\text { free ALT-FC } 2\end{array}$ & 39 & Very low \\
\hline Combs, 2014 & USA & $\mathrm{R}$ & 8 & n.a. & 4 & RA-MC 7, ORAM-MC 1 & n.a. & Very low \\
\hline Lin, 2014 & Taiwan & $\mathrm{R}$ & 1 & 72 & 1 & ALT-FC & 6 & Very low \\
\hline Fujiki, 2015 & Japan & $\mathrm{R}$ & 1 & 64 & 0 & ALT-FC & 14 & Very low \\
\hline Ryu, 2015 & USA & $\mathrm{R}$ & 1 & 65 & 1 & S-M & $14.1(1-56)$ & Very low \\
\hline Scaglioni, 2015 & Taiwan & $\mathrm{R}$ & 2 & 67 & 2 & PMT-FC & 3 & Very low \\
\hline Hulika, 2016 & India & $\mathrm{R}$ & 1 & 34 & 0 & ALT-MC & n.a. & Very low \\
\hline Chateau, 2016 & Belgium & $\mathrm{R}$ & 4 & 66 & 1 & 2 G-M, 1 RA-M, 1TFL-MC & n.a. & Very low \\
\hline
\end{tabular}

RA: Rectus abdominis flap; S: sartorius flap; TFL: tensor fascia latae flap; DIEP: deep inferior epigastric artery perforator flap; ALT: anterolateral tight flap; G: gracilis flap; RF: rectus femoris flap; QKIF: quadriceps keystone island flap; EOMF: external oblique myocutaneous flap; S-FAP: superficial femoral artery perforator flap; LD: latissimus dorsi flap; ORAM: oblique rectus abdominis flap; PMT: posterior posteromedial tight flap; M: muscular; FC: fasciocutaneous; MC: myocutaneous; LN: lymph node.

rectus femoris muscle (RF-M) in 117 cases $(21.7 \%)$, and gracilis muscle (G-M) in 98 patients $(18.2 \%)$. A splitthickness skin graft (STSG) was necessary to cover the muscle flap in 21 patients $(0.4 \%)$. Twenty-eight $(0.2 \%)$ patients required a fasciocutaneous or a myocutaneous flap to reconstruct the groin region (10 and 18 patients respectively).

Almost all patients had a unilateral harvesting, but bilateral flap harvesting was required in 17 patients
(3.2\%). Contralateral groin was the recipient site in 16 patients, while in other patients reconstruction was performed ipsilateral. Complete results are summarized in Table III.

In this subgroup the average surface defect size was significantly smaller $\left(63.9 \pm 32.9 \mathrm{~cm}^{2}\right.$ mean \pm SD) and the vast majority of papers not reported this data. Most of the papers reporting on inguinal reconstructions after vascular surgery were case reports or case series. 
Table III. Publications including patients following vascular surgery demanding for reconstructive inguinal surgery.

\begin{tabular}{|c|c|c|c|c|c|c|c|c|}
\hline Author, Year & Country & Design & $\begin{array}{c}\text { Number of } \\
\text { patients }\end{array}$ & $\begin{array}{l}\text { Age } \\
(\text { mean })\end{array}$ & $\begin{array}{l}\text { Coverage } \\
\text { technique }\end{array}$ & Skin graft & $\begin{array}{l}\text { Follow-up } \\
\text { (months) }\end{array}$ & GRADE \\
\hline Maser, 1997 & USA & $\mathrm{R}$ & 14 & 65 & S-M & Yes & 36 & Very Low \\
\hline Colwell, 2003 & USA & $\mathrm{R}$ & 9 & 72 & RF-M 3, RF-MC 1, S-M 5 & No & n.a. & Very Low \\
\hline Illig, 2004 & USA & $\mathrm{R}$ & 41 & n.a. & RF-M 35, G-M 3, S-M 2,RA-M 1 & n.a & n.a. & Very Low \\
\hline Morasch, 2004 & USA & $\mathrm{R}$ & 18 & 64 & G-M & No & 40 & Very Low \\
\hline Schutzer, 2005 & USA & $\mathrm{R}$ & 50 & n.a. & S-M & n.a. & n.a. & Low \\
\hline $\mathrm{Pu}, 2005$ & USA & $\mathrm{R}$ & 1 & 64 & S-M & No & n.a. & Very Low \\
\hline Shermak, 2005 & USA & $\mathrm{R}$ & 22 & n.a. & G-M 19, S-M 1, RA-M 1, RF-M 1 & Yes (3) & n.a. & Very Low \\
\hline Alkon, 2005 & USA & $\mathrm{R}$ & 40 & 65 & RF-M & Yes & n.a. & Very Low \\
\hline Khainga, 2006 & Kenya & $\mathrm{R}$ & 1 & 49 & RA-MC & No & n.a. & Very Low \\
\hline Armstrong, 2007 & USA & $\mathrm{R}$ & 86 & & S-M & & n.a. & Low \\
\hline Fodor, 2008 & Israel & $\mathrm{R}$ & 1 & 72 & RA-MC & No & n.a. & Very Low \\
\hline Ducic, 2008 & USA & $\mathrm{R}$ & 4 & 79 & G-M & Yes & n.a. & Very Low \\
\hline Qi, 2008 & China & $\mathrm{R}$ & 2 & n.a. & RA-MC & No & n.a. & Very Low \\
\hline Landry, 2009 & USA & $\mathrm{P}$ & 20 & 67 & S-M & No & n.a. & Very Low \\
\hline Qi, 2009 & China & $\mathrm{R}$ & 13 & 49 & RA-MC & No & n.a. & Very Low \\
\hline Chateau, 2010 & Belgium & $\mathrm{R}$ & 4 & 66 & G-M 2, RA-M 1,TFL-MC 1 & Yes & n.a. & Very Low \\
\hline Fischer, 2012 & USA & $\mathrm{R}$ & 146 & 66 & S-M 68, RF-M 69, ALT-MC 9 & No & n.a. & Low \\
\hline Kulkarni, 2012 & India & $\mathrm{R}$ & 1 & 60 & Posterior scrotal artery flap & No & $3 w$ & Very Low \\
\hline De Santis, 2013 & Italy & $\mathrm{R}$ & 1 & 52 & $\mathrm{RA}-\mathrm{MC}+\mathrm{S}-\mathrm{M}$ & No & n.a. & Very Low \\
\hline Wimmers, 2013 & USA & $\mathrm{R}$ & 1 & 58 & RA-M & Yes & n.a. & Very Low \\
\hline Shih, 2013 & Taiwan & $\mathrm{R}$ & 9 & 54 & $\begin{array}{l}\text { G-M 4, Local flap 1, ALT-MC } 1 \text {, } \\
\text { primary closure } 1 \text {, ALT-MC } 2\end{array}$ & Yes & 14 & Very Low \\
\hline Nelson, 2014 & USA & $\mathrm{R}$ & 43 & 70 & RF-M & No & n.a. & Very Low \\
\hline LoGiudice, 2014 & USA & $\mathrm{R}$ & 39 & 60 & ALT-FC 28, ALT-MC 2, RA-MC 10 & No & n.a. & Very Low \\
\hline May, 2015 & USA & $\mathrm{R}$ & 17 & n.a. & G-M 3, S-M 10, RF-M 4 & n.a & n.a. & Very Low \\
\hline Zelken, 2016 & Taiwan & $\mathrm{P}$ & 8 & 48 & VL-MC 4, ALT-MC 3, ALT-FC 1 & No & n.a. & Low \\
\hline Ali, 2016 & USA & $\mathrm{R}$ & 64 & 64 & G-M & n.a. & n.a. & Low \\
\hline Ryu, 2016 & USA & $\mathrm{R}$ & 29 & 65 & S-M & n.a & 14 & Very Low \\
\hline
\end{tabular}

S-M: Sartorius muscle flap; M: muscle; MC: myocutaneous; FC: fasciocutaneous; RF: rectus femoris flap; G: grafîcilis flap; RA: rectus abdominis flap; TFL: tensor fascialatae flap; ALT: anterolateral tight flap; VL: vastus lateralis flap.

Table IV. Complications reported by frequency (\%) for the subgroups of oncological resections and vascular surgery.

\begin{tabular}{lcr}
\hline Complications & Subgroup of oncological resections & Subgroup of vascular surgery \\
\hline Seroma & $34.4 \%$ & $7.5 \%$ \\
Infection & $22.9 \%$ & $14.4 \%$ \\
Flap dehiscence/delayed healing & $20.6 \%$ & $40.8 \%$ \\
Partial flap necrosis & $18.7 \%$ & $12.1 \%$ \\
Hematoma & $13.3 \%$ & $8.8 \%$ \\
Flap loss & $5.6 \%$ & $5.8 \%$ \\
Reintervention rate & $19.3 \%$ & $19.8 \%$ \\
\hline
\end{tabular}

The subgroup of miscellaneous patients. Other indications for inguinal reconstruction consisted of trauma, infection, post-burn contractions and visceral surgery. Reconstructive surgery was performed with pedicled fasciocutaneous and myocutaneous flaps harvested from the ipsilateral side of the patient's body, using either ALT-FC, vastus lateralismyocutaneous (VL-MC) or ALT-MC (Tables II and III). In only one case the flap was used in the contralateral groin.

\section{Complications}

The subgroup of oncological resections. In 28/33 papers $(85 \%)$ concerning oncologic patients reports on complications were included (Table IV) $(2,21,22,32-35$, $37-39,41-57)$. Seroma was the most frequent postoperative complication; six papers reported about this complication and the incidence was $34.4 \%(2,21,32,37,45,58)$. Other 
reported complications were, in decreasing order of percentage, (number of papers, percentage): infection $(6$, $22.9 \%)(2,22,32,37,39,42)$, wound dehiscence/delayed healing $(6,20.6 \%)(2,37,39,47,52,53)$, partial flap necrosis $(8,18.7 \%)(35,41,42,46,48,53,54,58)$, hematoma formation $(3,13.3 \%)(2,32,35)$ and flap loss $(2$, $5.6 \%$ ) (48). Complications not directly involving the flap were abdominal wall hernia in patients treated with RA flap $(2,15 \%)(35,54)$ and lymphedema of the inferior limb (4, $39.3 \%)(32,33,42,43,45)$. The estimated re-intervention rate was approximately $19 \%$, and 26 papers reported these data $(26 / 33,78 \%)(21,22,32-34,36-38,41-45,47-60)$.

The subgroup of vascular surgery. In 17/22 (77\%) of papers on patients in the subgroup of vascular surgery reports on complications were included $(2,6,7,10,11,14-19,21-26)$. Post-surgical wound dehiscence and consequent delayed healing was the most common complication (40.8\%) $(2,7$, $17,19,21)$. Other complications in decreasing order of incidence were (number of papers, percentage): seroma formation $(6,7.5 \%)(2,6,17,19,21,23)$, hematoma formation $(5,8.8 \%)(2,6,16-18)$ infection $(4,14.4 \%)(2,14$, $17,22)$, partial flap necrosis $(4,12.1 \%)(6,16,23,24)$, venous congestion $(1,11.1 \%)(26)$. All complications are summarized in Table IV.

The subgroup of miscellaneous patients. In this subgroup of patients, the frequency of complications was underreported with a single dehiscence and partial flap necrosis.

\section{Discussion}

The main finding of this systematic literature review of inguinal defects demanding reconstructive surgery was the presence of two main subgroups of surgical patients: those following oncological resections, and those who presented complications following vascular surgery. Another important finding was the lack of prospective studies, and the heterogeneous and disparate reporting on this common complication to surgery of the inguinal region, making metaanalyses impossible to perform. Reporting standards would facilitate research in this field, and could elevate the level of knowledge by defining a more evidence-based guide for reconstruction.

For all patients undergoing reconstructive inguinal surgery, regardless of aetiology, it is essential to fill out dead space, and provide a well-vascularised and metabolically active tissue to serve as a flap.

Patients who underwent inguinal reconstructive surgery for oncological reasons were younger, and had less comorbidities (1). For this subgroup of patients the myocutaneous flaps were the most used, approximately in $2 / 3$ of the patients. These flaps combine the advantages of having a well- vascularised tissue and a cutaneous island to cover the skin defect without employing STSG. Among the myocutaneous flaps RA-MC and ALT-MC were the most used, and both offer an excellent arc of rotation. However, considering the relevant donor site morbidity (resulting in an abdominal wall hernia) of RA-MC flap, ALT-MC seemed to be the flap of choice in unilateral groin reconstruction. Moreover, this flap has a long pedicle lying in a distant and non-irradiated field, with a big arc of rotation and a reliable vasculature and the possibility to be harvested as chimeric flap, with maximal exploitation of its vascularized components, including skin paddle, vastus lateralis and fascia lata (61). Muscle flaps such as G-M, S-M, and RF-M were rarely used for coverage of these wounds. Instead, fasciocutaneous flaps were moderately employed, probably because the absence of a muscle layer was limiting their advantages, especially in cases of deep defects or radical nodal dissection.

Recent literature suggests that the oncological resection subgroup was more likely to suffer from lymphatic leakage and seroma formation, due to the frequently associated nodal radicalisation, reaching almost $90 \%$. Muscle components potentially help treating these conditions (61), making the possibility to harvest the ALT flap associated to the vastus lateralis muscle (composite), particularly appealing (61). In the case of recurrent lymphatic complication such ad leaks or lymphocele, a lymphatic mapping should be considered during surgery $(61,62)$. $\mathrm{Pu}$ et al. recently described the use of a lymphatic mapping and a S-M flap to successfully treat a recalcitrant lymphorrea.

Patients undergoing oncologic resections reported higher infection-related complication rates, and a relatively higher flap necrosis rate was reported. These complications may be the result of the remarkably higher average cutaneous defect size when compared with vascular patients $\left(252.64 \mathrm{~cm}^{2} \mathrm{vs}\right.$. $63.88 \mathrm{~cm}^{2}$ ), the need for a skin paddle, and the presence of neoadjuvant radiotherapy in a considerable part of these patients $(83.2 \%)$, features leading to higher flap complications rates $(63)$.

In the subgroup of vascular surgery requiring inguinal reconstructive surgery, the patients were older compared with the oncological group, with a high burden of cardiovascular comorbidity, which is consistent with literature (64). These comorbidities might result in a generally higher risk of complications with secondary infection involving mainly subcutaneous layers, and vascular structures with a relative skin involvement. Vascular surgery site infections can threaten the success of the surgical procedure, but also put the entire limb at risk. Mortality rates up to $58 \%$, and morbidity of $79 \%$ have been reported $(8,64,65)$. Up to $60 \%$ of the chronically infected wounds are from biofilmproducing bacteria, from both gram-positive and -negative species such as Staph. aureus, Streptococci sp., E. coli, and K. pneumoniae. 
The demonstrated smaller surface defects reported in the literature matches the topographic features of the complications of vascular surgery, where wounds break down because of insufficient vascularisation and contamination. The cutaneous involvement is less striking than the important undermining of the wound edges. Considering these two conditions (particularly prone to infections and presenting cavity spaces), muscle flaps seem to be the best option in the subgroup of patients following vascular surgery. S-M and RF-M flaps were largely the most used. S-M flap transposition is a simple and fast procedure to lower post-operative complication rate without significant donor site morbidity regardless of the type of primary inguinal surgery, but may be insufficient in cases of larger defects, which instead might require a STSG. RF-M flap provides a bigger volume of tissue than SM, and can be harvested with a skin island, however it is technically more demanding and implies higher donor site morbidity in terms of weakening leg extension. Hence, if a moderate size skin island is required, a gracilis myocutaneous (G-MC) flap may be preferred because of minimal donor site morbidity, and ease of harvesting (6). If a large quantity of muscle is required RF-M flap with distal insertion harvesting seems to be the best choice (1). Flaps for covering inguinal defects after vascular surgery, despite presenting an inferior rate of partial flap necrosis, presented a higher incidence of wound dehiscence associated to delayed healing of approximately $40 \%$. This may be due to the large use of the S-M flap in the vascular surgery subgroup, which despite being easily raised, presents a segmentary vascularisation (Type IV Mathes and Nahai classification of muscle flaps) (66), which may lead to suboptimal flap perfusion and consequent wound breakdown. Moreover, the common practice of skin grafting over muscle flaps, which are more abundant in this group, may explain a higher rate of delayed healing issues. Routine preventive use of muscle flaps after vascular procedures might be needed in selected cases. This seems a reasonable option, particularly when considering the preventive use of S-M flap $(67,68)$.

The lack of reporting on antibiotic therapy is striking, and could hence not be evaluated in this study. Surely, the results of culture and the antibiotic strategy influence the results of inguinal reconstructive surgery, however, it is not reported sufficiently in the literature.

The combination of negative pressure wound therapy (NPWT) and flap surgery was not amenable for analysis because of the rare reporting. NPWT in patients after vascular surgery has been found to be superior to traditional alginate therapy in terms of wound healing and costeffectiveness (69). However, the results of combining flap surgery and NPWT has not been properly evaluated.

Ideally, the results of inguinal reconstruction, with or without NPWT, should be addressed in randomized controlled trials (RCT). Probably such RCT should be performed separately for the subgroups of oncological resections and vascular surgery, due to differences shown in this study in etiology and demand on reconstructive surgical approach.

\section{Limitations}

The majority of included studies were small (27 case reports in the oncological group, and 12 in the vascular group), retrospective case series, and were graded as very low in quality according to GRADE (4). Heterogeneous reporting with lack of detailed data on previous indication for surgery, outcomes and complications, was striking and hampered the possibility to make robust statistical analysis of the data, and thus to make valid conclusions. The lack of data also resulted in the exclusion of a considerable amount of papers. The subgroups of oncological resection, vascular surgery and miscellaneous were different in age, comorbidity and primary surgical procedure with different demands on reconstructive surgery, and hence no inter-group comparison testing was performed.

\section{Conclusion}

Reconstruction of inguinal defects following surgery needs to be addressed on a case-by-case basis, considering the initial etiology and the anatomic features of resulting defects. After oncological resection, the threshold for flap surgery should be low, and preferably a musculocutaneous flap should be used. After vascular surgery, the sartorius muscle flap transposition offers a simple and efficient solution, and routine preventive procedure with use of muscle flaps might be needed in a few selected cases. Introduction of reporting standards would facilitate further research in this field.

\section{Conflicts of Interest}

The Authors have no conflicts of interest to disclose.

\section{References}

1 Murthy V and Gopinath KS: Reconstruction of groin defects following radical inguinal lymphadenectomy: an evidence based review. Indian J Surg Oncol 3: 130-138, 2012.

2 LoGiudice JA, Haberman K and Sanger JR: The anterolateral thigh flap for groin and lower abdominal defects: a better alternative to the rectus abdominis flap. Plast Reconstr Surg 133: 162-168, 2014.

3 Bandyk DF: Vascular surgical site infection: risk factors and preventive measures. Semin Vasc Surg 21: 119-123, 2008.

4 Moher D, Liberati A, Tetzlaff J, Altman DG and Group P: Preferred reporting items for systematic reviews and metaanalyses: the PRISMA statement. BMJ 339: b2535, 2009. 
5 Schunemann HJ, Oxman AD, Brozek J, Glasziou P, Jaeschke R, Vist GE, Williams JW Jr, Kunz R, Craig J, Montori VM, Bossuyt P, Guyatt GH and GRADE Working Group: Grading quality of evidence and strength of recommendations for diagnostic tests and strategies. BMJ 336: 1106-1110, 2008.

6 Ali AT, Rueda M, Desikan S, Moursi MM, An R, Spencer H, Rueda S and Eidt JF: Outcomes after retroflexed gracilis muscle flap for vascular infections in the groin. J Vasc Surg 64: 452457, 2016.

7 Alkon JD, Smith A, Losee JE, Illig KA, Green RM and Serletti JM: Management of complex groin wounds: preferred use of the rectus femoris muscle flap. Plast Reconstr Surg 115: 776-784, 2005.

8 Armstrong PA, Back MR, Bandyk DF, Johnson BL and Shames ML: Selective application of sartorius muscle flaps and aggressive staged surgical debridement can influence long-term outcomes of complex prosthetic graft infections. J Vasc Surg 46: 71-78, 2007

9 Chateau F, Duisit J, Lengele B and Vanwijck R: Techniques for coverage of infected vascular grafts in the groin. Acta Chir Belg 110: 487-491, 2010.

10 De Santis F, Chaves Brait CM, Caravelli G, Pompei S and Di Cintio V: Salvage of infected vascular graft via 'perivascular venous banding' technique coupled with rectus abdominis myocutaneous muscle flap transposition. Vascular 21: 17-22, 2013

11 Ducic I, Dayan JH, Attinger CE and Curry P: Complex perineal and groin wound reconstruction using the extended dissection technique of the gracilis flap. Plast Reconstr Surg 122: 472-478, 2008.

12 Fodor M, Fodor L and Ciuce C: Simultaneous extra-anatomic bypass and abdominal "flag flap" for lower limb salvage in a patient with severe post-bypass anastomotic groin infection. Acta Chir Belg 108: 738-740, 2008.

13 Illig KA, Alkon JE, Smith A, Rhodes JM, Keefer A, Doyle A, Serletti J, Shortell CK, Davies MG and Green RM: Rotational muscle flap closure for acute groin wound infections following vascular surgery. Ann Vasc Surg 18: 661-668, 2004.

14 Khainga SO: Extended pedicle rectus abdominis myocutaneous flap for groin reconstruction: case report. East Afr Med J 83: 575-579, 2006.

15 Kulkarni AA, Bhatia SH, Abhyankar SV, Kulkarni MD and Singh RR: Posterior scrotal artery flap to cover a groin defect: a new technique. Indian J Surg 75: 52-53, 2013.

16 Maser B, Vedder N, Rodriguez D and Johansen K: Sartorius myoplasty for infected vascular grafts in the groin. Safe, durable, and effective. Arch Surg 132: 522-525, 1997.

17 May BL, Zelenski NA, Daluvoy SV, Blanton MW, Shortell CK and Erdmann D: Salvage of exposed groin vascular grafts with early intervention using local muscle flaps. Plast Reconstr Surg Glob Open 3: e514, 2015.

18 Morasch MD, Sam AD 2nd, Kibbe MR, Hijjawi J and Dumanian GA: Early results with use of gracilis muscle flap coverage of infected groin wounds after vascular surgery. J Vasc Surg 39: 1277-1283, 2004

19 Nelson JA, Fischer JP, Mackay JD, Mirzabeigi MN, Cabiling DS, Kovach SJ, Serletti JM and Kanchwala S: The limited incision harvest of the rectus femoris flap for complex groin wound management. Ann Plast Surg 73: S161-164, 2014.

20 Qi F, Gu J and Shi Y: Difficult groin reconstruction using contralateral rectus abdominis myocutaneous flap. Plast Reconstr Surg 121: 147e-148e, 2008.
21 Qi F, Zhang Y and Gu J: Repairs of complex groin wounds with contralateral rectus abdominis myocutaneous flaps. Microsurgery 29: 199-204, 2009.

22 Ryu DY, Jung HJ, Ramaiah VG, Rodriguez-Lopez JA and Lee SS: Infected Groin (Graft/Patch): Managed with Sartorious Muscle Flap. Vasc Specialist Int 32: 11-16, 2016.

23 Schutzer R, Hingorani A, Ascher E, Markevich N, Kallakuri S and Jacob T: Early transposition of the sartorius muscle for exposed patent infrainguinal bypass grafts. Vasc Endovascular Surg 39: 159-162, 2005.

24 Shih PK, Cheng HT, Wu CI, Chang SC, Chen HC and Chen HH: Management of infected groin wounds after vascular surgery. Surg Infect (Larchmt) 14: 325-330, 2013.

25 Wimmers EG and Lifchez SD: Intercostal artery-based rectus abdominis muscle flap for groin reconstruction. J Plast Reconstr Aesthet Surg 67: e118-119, 2014.

26 Zelken JA, AlDeek NF, Hsu CC, Chang NJ, Lin CH and Lin $\mathrm{CH}$ : Algorithmic approach to lower abdominal, perineal, and groin reconstruction using anterolateral thigh flaps. Microsurgery 36: 104-114, 2016.

27 Aygit AC, Onat R, Aydin Y and Orak F: Contralateral rectus abdominis muscle flap coverage for the management of a complicated groin defect. Ann Plast Surg 38: 307-308, 1997.

28 Kuvat SV, Yanar H, Bicer A, Tuncer S, Ozalp B and Topalan M: Reconstruction of complex groin defects with inferior epigastric artery-based rectus abdominis muscle flaps: report of two cases. Ulus Travma Acil Cerrahi Derg 17: 273-276, 2011.

29 Sen C, Ozgenel Y and Ozcan M: A single tensor fasciae latae musculocutaneous and fascia flap for composite reconstruction of urogenital and groin defect. Br J Plast Surg 58: 724-727, 2005.

30 Mizukami T, Fujiwara M, Ishikawa K, Aoyama S and Fukamizu $\mathrm{H}$ : Reconstruction for extensive groin hidradenitis suppurativa using a combination of inferior abdominal flap and medial thighlift: a case report. Aesthetic Plast Surg 38: 745-748, 2014.

31 Nangole F, Biribwa P and Khainga S: Pedicled anterior lateral thigh flap in managing a bilateral groin contracture. Case Rep Surg 2014: 451356, 2014.

32 Behan FC, Paddle A, Rozen WM, Ye X, Speakman D, Findlay MW and Henderson MA: Quadriceps keystone island flap for radical inguinal lymphadenectomy: a reliable locoregional island flap for large groin defects. ANZ J Surg 83: 942-947, 2013.

33 Brierly RD, Pereira JA and Arnstein PM: Use of a vertical rectus abdominis myocutaneous flap in bilateral groin dissection for recurrent carcinoma of the penis. Urol Int 61: 243-246, 1998.

34 Chao AH, McCann GA and Fowler JM: Bilateral groin reconstruction with a single anterolateral thigh perforator flap as an alternative to traditional myocutaneous flaps. Gynecol Oncol Case Rep 9: 15-17, 2014.

35 Daigeler A, Simidjiiska-Belyaeva M, Drucke D, Goertz O, Hirsch T, Soimaru C, Lehnhardt $M$ and Steinhau HU: The versatility of the pedicled vertical rectus abdominis myocutaneous flap in oncologic patients. Langenbecks Arch Surg 396: 1271-1279, 2011.

36 Deo SV, Nootan KS, Niranjan B and Dinesh K: Vertical rectus abdominis myocutaneous flap cover for lower abdomen, chest wall, groin and thigh defects following resection of malignant tumours. Indian J Cancer 38: 33-37, 2001.

37 Evriviades D, Raurell A and Perks AG: Pedicled anterolateral thigh flap for reconstruction after radical groin dissection. Urology 70: 996-999, 2007. 
38 Mohamed SA, Sakr MF, El-Hammadi HA, Moussa MM and ElSharaky MM: The use of the 'TRAM' flap in some oncological problems. Int Surg 85: 347-352, 2000.

39 Parrett BM, Winograd JM, Garfein ES, Lee WP, Hornicek FJ and Austen WG Jr.: The vertical and extended rectus abdominis myocutaneous flap for irradiated thigh and groin defects. Plast Reconstr Surg 122: 171-177, 2008.

40 di Summa PG, Tremp M, Meyer S, Schaefer DJ, Kalbermatten DF and Raffoul W: The Combined Pedicled Anterolateral Thigh and Vastus Lateralis Flap as Filler for Complex Perineal Defects. Ann Plast Surg 75: 66-73, 2015.

41 Tabatabaei S and McDougal WS: Primary skin closure of large groin defects after inguinal lymphadenectomy for penile cancer using an abdominal cutaneous advancement flap. J Urol 169: 118-120, 2003.

42 Agarwal AK, Gupta S, Bhattacharya N, Guha G and Agarwal A: Tensor fascia lata flap reconstruction in groin malignancy. Singapore Med J 50: 781-784, 2009.

43 Bharath SP, Madhusudan G and Manjunath S: Pedicled anterolateral thigh flap for contralateral groin composite defect. Indian J Plast Surg 43: 103-105, 2010.

44 Cedidi CC, Felmerer G and Berger A: Management of defects in the groin, thigh, and pelvic region with modified contralateral TRAM/VRAM flaps. Eur J Med Res 10: 515-520, 2005.

45 El-Sherbiny M: Limb sparing surgical resection of groin sarcoma. Surgical approach and reconstructive options. J Egypt Natl Canc Inst 20: 281-293, 2008.

46 Friji MT, Suri MP, Shankhdhar VK, Ahmad QG and Yadav PS: Pedicled anterolateral thigh flap: a versatile flap for difficult regional soft tissue reconstruction. Ann Plast Surg 64: 458-461, 2010.

47 Fujiki M, Miyamoto S, Arikawa M and Sakuraba M: Combined Use of Anterolateral Thigh and Gluteal Fold Flaps for Complex Groin Reconstruction. Plast Reconstr Surg Glob Open 3: e541, 2015.

48 Lannon DA, Ross GL, Addison PD, Novak CB, Lipa JE and Neligan PC: Versatility of the proximally pedicled anterolateral thigh flap and its use in complex abdominal and pelvic reconstruction. Plast Reconstr Surg 127: 677-688, 2011.

49 Lin CT, Wang CH, Ou KW, Chang SC, Dai NT, Chen SG, Chen TM and Tzeng YS: Clinical applications of the pedicled anterolateral thigh flap in reconstruction. ANZ J Surg 87: 499-504, 2017.

50 Melis P, Bos KE and Horenblas S: Primary skin closure of a large groin defect after inguinal lymphadenectomy for penile cancer using a skin stretching device. J Urol 159: 185-187, 1998.

51 Miyamoto S, Fujiki M, Nakatani F, Kobayashi E, Sakisaka M and Sakuraba M: Reconstruction of complex groin defects after sarcoma resection. Ann Plast Surg 78: 443-447, 2017.

52 Ramseier LE, Dumont CE, Bode-Lesniewska B, Lombriser N and Exner GU: Results of treatment of malignant soft tissue tumours in the groin. Scand J Plast Reconstr Surg Hand Surg 42: 241-245, 2008.

53 Rifaat MA and Abdel Gawad WS: The use of tensor fascia lata pedicled flap in reconstructing full thickness abdominal wall defects and groin defects following tumor ablation. J Egypt Natl Canc Inst 17: 139-148, 2005.

54 Saito A, Minakawa H, Saito N, Isu K, Hiraga H and Osanai T: Clinical experience using a tensor fascia lata flap in oncology patients. Surg Today 44: 1438-1442, 2014.
55 Sanchez Medina MT, Lima Sanchez J, Fernandez-Palacios J and Garcia Duque O: Soft tissue sarcoma in the thigh and groin. Reconstruction using vertical rectus abdominis myocutaneous flap. Cir Esp 92: 693-694, 2014.

56 Scaglioni MF, Enrique Carrillo Jimenez L, Kuo YR and Chen YC: Pedicled posteromedial thigh (PMT) flap: A new alternative for groin defect reconstruction. Microsurgery 37: 339-343, 2015.

57 Zeng A, Xu J, Yan X, You L and Yang H: Pedicled deep inferior epigastric perforator flap: an alternative method to repair groin and scrotal defects. Ann Plast Surg 57: 285-288, 2006.

58 Zhang R, Wang C, Chen Y, Zheng B and Shi Y: The use of unilateral or bilateral external oblique myocutaneous flap in the reconstruction of lower abdominal wall or groin defects after malignant tumor resection. J Surg Oncol 110: 930-934, 2014.

59 Hulika N, Naru RR, Azhagamuthu Inamdar B and Chandra A: Contralateral Pedicled Anterolateral Thigh Flap (ATL) for Upper Thigh Defect in the Era of Free ATL? World J Plast Surg 5: 194197, 2016.

60 Kuntscher MV, Mansouri S, Noack $\mathrm{N}$ and Hartmann B: Versatility of vertical rectus abdominis musculocutaneous flaps. Microsurgery 26: 363-369, 2006.

$61 \mathrm{Ng} \mathrm{RW}$, Chan JY, Mok V and Li GK: Clinical use of a pedicled anterolateral thigh flap. J Plast Reconstr Aesthet Surg 61: 158$164,2008$.

62 Erba P, Wettstein R, Rieger UM, Haug M, Pierer G, Kalbermatten DF: A study of the effect of sartorius transposition on lymph flow after ilioinguinal node dissection. Ann Plast Surg 61: 310-313, 2008.

$63 \mathrm{Pu}$ LL, Jahania MS and Mentzer RM Jr.: Successful management of recalcitrant groin lymphorrhoea with the combination of intraoperative lymphatic mapping and muscle flap. J Plast Reconstr Aesthet Surg 59: 1363-1366, 2006.

64 Cherry KJ Jr, Roland CF, Pairolero PC, Hallett Jr JW, Meland NB, Naessens JM, Gloviczki $P$ and Bower TC: Infected femorodistal bypass: is graft removal mandatory? J Vasc Surg 15: 295-303, 1992.

65 Kikta MJ, Goodson SF, Bishara RA, Meyer JP, Schuler JJ and Flanigan P: Mortality and limb loss with infected infrainguinal bypass grafts. J Vasc Surg 5: 566-571, 1987.

66 Mathes SJ and Nahai F: Classification of the vascular anatomy of muscles: experimental and clinical correlation. Plast Reconstr Surg 67: 177-187, 1981 .

67 Fischer JP, Nelson JA, Mirzabeigi MN, Wang GJ, Foley PJ, Wu LC, Woo EY and Kanchwala S: Prophylactic muscle flaps in vascular surgery. J Vasc Surg 55: 1081-1086, 2012.

68 Wu LC, Djohan RS, Liu TS, Chao AH, Lohman RF and Song $\mathrm{DH}$ : Proximal vascular pedicle preservation for sartorius muscle flap transposition. Plast Reconstr Surg 117: 253-258, 2006.

69 Monsen C, Acosta S, Mani K and Wann-Hansson C: A randomised study of NPWT closure versus alginate dressings in peri-vascular groin infections: quality of life, pain and cost. J Wound Care 24: 252-260, 2015. 